\title{
"Pattern of Stroke in Diabetic and Non-Diabetic Patients Admitted at a Tertiary Care Hospital, a Cross Sectional Study"
}

\author{
Sohail Ahmed Siddiqui ${ }^{1}$, Mubashir Ahmed ${ }^{2 *}$, Abdul Haq ${ }^{1}$, Atif Ahmed ${ }^{1}$, Pir Abdul Hayee ${ }^{3}$ Qureshi $^{\text {Abres }}$ \\ ${ }^{1}$ Department of Medicine, Liaquat University of Medical and Health Sciences (LUMHS), Hospital, Hyderabad, Sindh \\ ${ }^{2}$ Kharadar General Hospital, Aga Khan Road, Kharadar, Karachi, Pakistan. \\ ${ }^{3}$ Muhammadi Medical College, Mirpurkhas.
}

Corresponding author: Mubashir Ahmed, Research Department, Kharadar General Hospital, Aga Khan Road, Kharadar, Karachi74000, Pakistan.

Received date: April 06, 2021: Accepted date: July 15, 2021: Published date: September 04, 2021

Citation: Sohail A Siddiqui, Ahmed M, Haq A, Ahmed A, Pir A Hayee Qureshi (2021) "Pattern of Stroke in Diabetic and Non-Diabetic Patients Admitted at a Tertiary Care Hospital, a Cross Sectional Study". J. of Clin Case Rep and Stu 2(5); DOI: 10.31579/2690-8808/073

Copyright: (C2021: Mubashir Ahmed. This is an open access article distributed under the Creative Commons Attribution License, which permits unrestricted use, distribution, and reproduction in any medium, provided the original work is properly cited.

\begin{abstract}
Objective: To determine the frequency of diabetic among stroke patients and to compare the pattern of stroke in diabetic and non-diabetic stroke patients admitted at a tertiary care hospital in Hyderabad, Sindh.

Methods: A cross sectional study enrolled 148 consecutive adult acute stroke patients admitted at Liaquat University Hospital, Hyderabad, during Sep 2014 to Feb 2015. Demographic, clinical, radio-imaging and laboratory data were collected on structured questionnaire to identify diabetes, type of stroke and different risk factors of stroke. Data was entered and analysed by using SPSS version 16. Association was seen by using Pearson's Chi-square test and Independen $\mathrm{t}$ test. A P value of $<0.05$ was considered statistically significant.

Results: A total of 148 acute stroke cases were enrolled in the study. Males were 92 (62\%). Mean age of study participants was $51.21 \pm 10.19$ years. Diabetes was found in $104(70.3 \%)$ stroke patients. Ischemic stroke was seen in $101(68.2 \%)$ and haemorrhagic stroke seen in 47 (31.8) stroke patients. Diabetes was more common in ischemic stroke 81 (80.2) as compared to haemorrhagic stroke $23(48.9 \%)(\mathrm{P}<0.05)$. Hospital mortality of stroke patients was $37(25 \%)$. No difference of mortality in diabetic and non-diabetic ( $\mathrm{P}>0.05)$ stroke patients was recorded.

Conclusion: Diabetes was found in majority of stroke patients. Ischemic stroke was more common than haemorrhagic stroke. Ischaemic stroke is more prevalent in diabetic whereas haemorrhagic stroke was more in non-diabetic stroke patients. Prognosis of stroke was bad in both diabetic and non-diabetic stroke patients.
\end{abstract}

Key words: stroke, ischemic, haemorrhagic, diabetes mellitus

\section{Introduction}

Stroke is the second most common cause of death and the first most frequent cause of permanent disability in the world [1]. World Health Organization (WHO) estimates that 5.5 million people died of stroke in 2002, and roughly 20 percent of these deaths occurred in South Asia [2]. India reported the annual incidence of stroke as 145 per 100,000 persons per year [3]. China reported total average age-adjusted incidence of stroke range from 116 to 219 per 100000 per year [4]. In Pakistan only single study reported the prevalence of stroke was $4.8 \%$ with no difference in male to female [5]. Also, the reported study was based on verbal questions on stroke or illness like stroke without confirmation of stroke through CT scan or MRI. Pakistan stroke society claimed that estimated annual incidence of stroke was 250 per 100,000 population, translating to total population, 350,000 new cases of stroke were added every year [6].
A stroke is the rapid loss of brain function due to disturbance in the blood supply to the brain. This can be due to ischemia, lack of blood flow, caused by blockage by thrombosis, arterial embolism, or due to hemorrhage [7]. As a result, the affected area of the brain cannot function, which might result in an inability to move one or more limbs on one side of the body, inability to understand or formulate speech, or an inability to see one side of the visual field [8]. Strokes can be classified into two major categories: ischemic and hemorrhagic stroke [9]. Ischemic strokes are those that are caused by interruption of the blood supply, while hemorrhagic strokes are the ones which result from rupture of a blood vessel or an abnormal vascular structure. About $88 \%$ of strokes are caused by ischemia and the remainder by hemorrhage [10]. 
Diabetes mellitus supposed to be an independent modifiable risk factor for stroke. Diabetes patients were 1.5 to 3 times at higher risk of having stroke as compared to the general population [11, 12]. Diabetes associated mortality and morbidity was greater in diabetic stroke patients as compared to non-diabetic stroke [13,14]. Stroke causes 20 percent of deaths in diabetic patients [1]. Substantially increasing diabetes prevalence every year across all age groups and race/ethnicity groups, the significance of diabetes as a separate risk factor for stroke is becoming more evidence [12]. Diabetes is clearly one of the most important risk factors for ischemic strokes, a large proportion of stroke patients have diagnosed with diabetes (16-24\%), especially younger stroke patients who has age less than 65 years of age [12].

No such epidemiological studies have been conducted in Pakistan to determine the pattern of stroke in diabetic and non-diabetic population. As burden of diabetes was high in Pakistan so assume high burden of stroke in our population. There was a paucity of stroke data from our population particularly about the pattern of stroke in diabetic and nondiabetic patients. Therefore the current study was aimed to identify the different patterns of stroke in diabetic and non-diabetic stroke patients.

\section{Material and Methods}

A cross sectional study was conducted at Liaquat University of Medical and Health Sciences (LUMHS), Hospital, Jamshoro/ Hyderabad, Sindh from Sep 2014 to Feb 2015. All consecutive adults of age 20 years or above admitted with clinical presentation of acute stroke during the study period, with or without diabetes, and later on stroke was confirmed on CT scan or MRI brain, were included in this study. All those patients who had head injury, receiving anticoagulant drugs or steroids prior to onset of stroke, and uncommon stroke caused by hyper-coagulation disorder, venous sinous, thrombosis, and vasculitis were excluded from the study.

Sample size calculation was based on the assumptions that anticipated prevalence of diabetes in stroke was $16 \%$ [5], absolute precision was 5\%, confidence level was $90 \%$, and $2 \%$ bound on error, the minimum sample size was calculated 148 stroke cases. So, a total of 148 consecutive confirmed stroke patients were included in the study after taking informed consent from each participants or their attendant. Structured questionnaire was used for data collection. After taking demographic information, study participants were assessed through clinical history, physical and neurological examination, radio-imaging and laboratory investigation to identify stroke, type of stroke, ischemic or haemorrhagic, and risk factors of stroke like diabetes, hypertension, hyperlipidaemia, ischemic heart disease, previous cerebrovascular accidents (CVA) and smoking [8, 9]. Laboratory investigations included, serum glucose fasting/ random, $\mathrm{HbAlc}$, and lipid profile. Fasting glucose $\geq 126 \mathrm{mg} / \mathrm{dl}$, random glucose $\geq$ $200 \mathrm{mg} / \mathrm{dl} \& \mathrm{HbA} 1 \mathrm{c} \geq 6.5 \mathrm{~m} \mathrm{~mol} / \mathrm{dl}$ were the standard measure used to diagnose diabetes mellitus [15]. Hyperlipidaemia was diagnosed if patients were on lipid lowering agents or with elevated serum cholesterol ( $\geq 200 \mathrm{mg} / \mathrm{dl}$ ) and / or triglyceride $(\geq 150 \mathrm{mg} / \mathrm{dl}$ ) and/ or a low high density lipoprotein level $(\leq 40 \mathrm{mg} / \mathrm{dl})$ and/or a high low density lipoproteins $(\geq 130)$ [16]. Hypertension was diagnosed [2] if patients were on anti-hypertensive drugs or have systolic blood pressure $\geq 140 \mathrm{mmHg}$ or diastolic blood pressure $\geq 90 \mathrm{mmHg}$ more than two readings during hospitalization. CT scan (computed tomography) or/and MRI (Magnetic
Resonance Imaging) of brain were also taken to identify the type of stroke (ischemic or haemorrhagic). Prospectively stroke patients outcome was recorded as survived or died through questionnaire. Study approval was taken from Ethics Review Committee (ERC) of LUMHS, Jamshoro.

Data Analysis: Data was entered and analyzed by using Statistical Package for Social Science (SPSS) Software version 16.0. Standard descriptive statistics were used to summarize the information recorded. Pearson's Chi-square test for categorical variables and Independent t test to compared means of continuous variables were used to see the correlation between diabetic and non-diabetic stroke patients. A P value of $<0.05$ was considered statistically significant.

\section{Results}

A total of 148 acute stroke cases were enrolled in the study. Male were 92 (62\%) with male to female ratio of 1.6:1. Mean age of study participants was $51.21 \pm 10.19$ years. Stroke cases were raised with increasing age and majority stroke cases 53 (35.8) were fallen in the age group of 60 years or above. Of 148 stroke cases, around two-third 101 (68.2) cases were ischemic stroke and one-third 47 (31.8) cases were haemorrhagic stroke. Ischemic to haemorrhagic stroke ratio was 2.1:1 (Table 1).

Diabetes was found in around two-third 104 (70.3\%) of stroke patients. Diabetic to non-diabetic stroke ratio was 2.4:1. Diabetes was more common in ischemic stroke 81 (80.2) as compared to haemorrhagic stroke 23 (48.9). The difference was statistically significant $(\mathrm{P}<0.05)$ (Table 1). Among diabetic, stroke cases were seen more 37 (35.6) in younger age groups ( $<50$ years) as compare to non-diabetic, where stroke cases were 12 (27.24) under 50 years. $(\mathrm{P}<0.05)$.

Of different risk factors of stroke, hypertension was the most common risk factor $113(76.4 \%)$ identified among study stroke patients. Followed by diabetes mellitus 104 (70.3\%), Hyperlipidemia 103 (69.6), smoking 68 (45.9\%), family history of diabetes $58(39.2 \%)$, previous history of IHD $44(29.7 \%)$, previous history of stoke $26(17.6 \%)$, family history of IHD $23(15.5 \%)$, and family history of stroke $16(10.8 \%)$ respectively (Table 1).

In study stroke patients, mostly means levels of lab indicators (glucose fasting/ glucose random/ HBA1c/ total cholesterol/ triglyceride/ LDL/ HDL) were lies within normal limits except glucose random and HBA1C. (See table2). When comparing means of these lab indicators among diabetic and non-diabetic stroke, the total cholesterol and LDL cholesterol mean levels differences were statistically significant $(\mathrm{P}<0.05)$. On the other hands when comparing means of lab indicators of ischemic stroke versus haemorrhagic stroke, the difference in the mean levels of all lab indicators were statistically significant $(\mathrm{P}<0.05)$ except triglyceride $(\mathrm{P}>$ 0.05) (See table 2).

Regarding stroke outcome, one-fourth 37 (25.0) of study stroke patients, were died in hospital. Including 23 (22.1) deaths in diabetic stroke and 14 (31.8) deaths in non-diabetic stroke. No statistical significant difference was found $(\mathrm{P}>0.05)$. While comparing deaths in haemorrhagic stroke 17 (36.2) verses ischemic stroke 20 (19.8), the difference was statistical significant $(\mathrm{P}<0.05)$. 


\begin{tabular}{|c|c|c|c|c|c|c|c|}
\hline Variables & $\begin{array}{l}\text { Total Stroke } \\
\text { cases }(n=148)\end{array}$ & $\begin{array}{c}\text { Ischemic } \\
\text { Stroke }(\mathrm{n}= \\
101)\end{array}$ & $\begin{array}{l}\text { Haemorrhagic } \\
\text { Stroke }(n=47)\end{array}$ & P Value & $\begin{array}{c}\text { Diabetic } \\
\text { Stroke }(\mathrm{n}= \\
104)\end{array}$ & $\begin{array}{l}\text { Non-diabetic } \\
\text { Stroke }(n=44)\end{array}$ & P Value \\
\hline Gender & & & & 0.082 & & & 0.810 \\
\hline Male & $92(62.2)$ & $58(57.4)$ & $34(72.3)$ & & $64(61.5)$ & $28(63.6)$ & \\
\hline Female & $56(37.8)$ & $43(42.6)$ & $13(27.3)$ & & $40(38.5)$ & $16(36.4)$ & \\
\hline Mean Age with SD & $51.21 \pm 10.19$ & $51.79 \pm 9.53$ & $49.96 \pm 11.51$ & 0.310 & $50.62 \pm 9.42$ & $52.61 \pm 11.82$ & 0.277 \\
\hline \multicolumn{8}{|l|}{ Age Category } \\
\hline $20-29$ years & $03(2.0)$ & $1(1.0)$ & $2(4.3)$ & & $1(1.0)$ & $02(4.5)$ & \\
\hline $30-39$ years & $12(8.1)$ & $7(6.9)$ & $5(10.6)$ & & $7(6.7)$ & $05(11.4)$ & \\
\hline $40-49$ years & $34(23.0)$ & $26(25.7)$ & $8(17.0)$ & & $29(27.9)$ & $05(11.4)$ & \\
\hline $50-59$ years & $46(31.1)$ & $30(29.7)$ & $16(34.0)$ & & $37(35.6)$ & $9(20.5)$ & \\
\hline$\geq 60$ years & $53(35.8)$ & $37(36.6)$ & $16(34.0)$ & & $30(28.8)$ & $23(52.3)$ & \\
\hline \multicolumn{8}{|l|}{ Risk factors } \\
\hline Previous H/o Stroke & $26(17.6)$ & $22(21.8)$ & $4(8.5)$ & 0.048 & $20(19.2)$ & $6(13.6)$ & 0.414 \\
\hline H/o Hypertension & $113(76.4)$ & $69(68.3)$ & $44(93.6)$ & 0.001 & $76(73.1)$ & $37(84.1)$ & 0.150 \\
\hline $\begin{array}{l}\text { H/o Ischemic heart } \\
\text { disease }\end{array}$ & $44(29.7)$ & $40(39.6)$ & $4(8.5)$ & 0.000 & $32(30.8)$ & $12(27.3)$ & 0.671 \\
\hline $\begin{array}{l}\text { Family history of } \\
\text { Diabetes }\end{array}$ & $58(39.2)$ & $51(50.5)$ & $7(14.9)$ & 0.000 & $48(46.2)$ & $10(22.7)$ & 0.008 \\
\hline $\begin{array}{l}\text { Family history of } \\
\text { Stroke }\end{array}$ & $16(10.8)$ & $12(11.9)$ & $4(8.5)$ & 0.539 & $8(7.7)$ & $8(18.2)$ & 0.060 \\
\hline Family history of IHD & $23(15.5)$ & $21(20.8)$ & $2(4.3)$ & 0.010 & $17(16.3)$ & $6(13.6)$ & 0.677 \\
\hline Hyperlipidemia & $103(69.6)$ & $79(78.2)$ & $24(51.1)$ & 0.001 & $79(76.0)$ & $24(54.5)$ & 0.010 \\
\hline Smoker & $68(45.9)$ & $49(48.5)$ & $19(40.4)$ & 0.358 & $52(50.0)$ & $16(36.4)$ & 0.128 \\
\hline \multicolumn{8}{|l|}{ Lab indicators } \\
\hline $\begin{array}{l}\text { Raised Glucose Fasting } \\
(\geq 126 \mathrm{mg} / \mathrm{dl})\end{array}$ & $40(27.0)$ & $34(33.7)$ & $6(12.8)$ & 0.008 & $40(38.5)$ & $0(0.0)$ & 0.000 \\
\hline $\begin{array}{l}\text { Raised Glucose Random } \\
(\geq 200 \mathrm{mg} / \mathrm{dl})\end{array}$ & $82(55.4)$ & $68(67.3)$ & $14(29.8)$ & 0.000 & $82(78.8)$ & $0(0.0)$ & 0.000 \\
\hline $\begin{array}{l}\mathrm{HBA1C}(\geq 6.5 \mathrm{~m} \mathrm{~mol} \\
\text { /dl) }\end{array}$ & $102(68.9)$ & $79(78.2)$ & $23(48.9)$ & 0.000 & $102(98.1)$ & $0(0.0)$ & 0.000 \\
\hline $\begin{array}{l}\text { Raised Total } \\
\text { Cholesterol } \\
(\geq 200 \mathrm{mg} / \mathrm{dl})\end{array}$ & $62(41.9)$ & $53(52.5)$ & $9(19.1)$ & 0.000 & $52(50.0)$ & $10(22.7)$ & 0.002 \\
\hline $\begin{array}{l}\text { Raised Triglyceride } \\
(\geq 150 \mathrm{mg} / \mathrm{dl})\end{array}$ & $67(45.3)$ & $48(47.5)$ & $19(40.4)$ & 0.419 & $51(49.0)$ & $16(36.4)$ & 0.157 \\
\hline $\begin{array}{l}\text { Raised LDL }(\geq \\
130 \mathrm{mg} / \mathrm{dl})\end{array}$ & $68(45.9)$ & $58(57.4)$ & $10(21.3)$ & 0.000 & $57(54.8)$ & $11(25.0)$ & 0.001 \\
\hline Low HDL $(<40 \mathrm{mg} / \mathrm{dl})$ & $27(18.2)$ & $24(23.8)$ & $3(6.4)$ & 0.011 & $21(20.2)$ & $6(13.6)$ & 0.345 \\
\hline Diabetes & & & & 0.000 & & & \\
\hline Yes & $104(70.3)$ & $81(80.2)$ & $23(48.9)$ & & & & \\
\hline No & $44(29.6)$ & $20(19.7)$ & $24(51.1)$ & & & & \\
\hline Type of Stroke & & & & & & & 0.000 \\
\hline Ischemic Stoke & $101(68.2)$ & & & & $81(77.9)$ & $20(45.5)$ & \\
\hline Haemorrhagic Stoke & $47(31.8)$ & & & & $23(22.1)$ & $24(54.5)$ & \\
\hline Outcome & & & & 0.032 & & & 0.213 \\
\hline Survive & $111(75.0)$ & $81(80.2)$ & $30(63.8)$ & & $81(77.9)$ & $30(68.2)$ & \\
\hline Died & $37(25.0)$ & $20(19.8)$ & $17(36.2)$ & & $23(22.1)$ & $14(31.8)$ & \\
\hline
\end{tabular}

Table 1: Characteristics of Study stroke cases $(N=148)$ 


\begin{tabular}{|l|c|l|l|l|l|l|}
\hline Lab Indicators & $\begin{array}{c}\text { Mean } \pm \text { SD } \\
\text { Total Stroke cases } \\
(\mathbf{n = 1 4 8})\end{array}$ & $\begin{array}{c}\text { Mean } \pm \text { SD } \\
\text { Ischemic Stroke } \\
(\mathbf{n = 1 0 1})\end{array}$ & $\begin{array}{c}\text { Mean } \pm \text { SD } \\
\text { Haemorrhagic } \\
\text { Stroke }(\mathbf{n}=\mathbf{4 7})\end{array}$ & $\begin{array}{c}\text { P Value } \\
\text { Mean } \pm \text { SD }\end{array}$ & $\begin{array}{c}\text { Mean } \pm \text { SD } \\
\text { Non-diabetic } \\
\text { Stroke }(\mathbf{n}=\mathbf{6 6})\end{array}$ & $\begin{array}{c}\text { P Value } \\
\text { Diabetic Stroke } \\
(\mathbf{n}=\mathbf{8 2})\end{array}$ \\
\hline Glucose Fasting & $110.39 \pm 39.28$ & $118.0 \pm 41.11$ & $94.0 \pm 29.27$ & $\mathbf{0 . 0 1 7}$ & $122.84 \pm 40.08$ & $80.95 \pm 12.92$ \\
\hline Glucose Random & $223.75 \pm 80.93$ & $241.6 \pm 79.93$ & $185.4 \pm 69.58$ & $\mathbf{0 . 0 5 1}$ & $255.11 \pm 76.69$ & $149.64 \pm 17.45$ \\
\hline HBA1C & $7.49 \pm 01.48$ & $7.8 \pm 1.41$ & $6.7 \pm 1.34$ & $\mathbf{0 . 3 0 1}$ & $8.20 \pm 1.17$ & $5.81 \pm 0.38$ \\
\hline $\begin{array}{l}\text { Serum } \\
\text { Cholesterol }\end{array}$ & $193.4 \pm 39.54$ & $203.0 \pm 38.17$ & $172.5 \pm 34.37$ & $\mathbf{0 . 1 7 1}$ & $202.44 \pm 38.84$ & $171.86 \pm 32.54$ \\
\hline $\begin{array}{l}\text { Serum } \\
\text { Triglyceride }\end{array}$ & $143.4 \pm 33.95$ & $145.1 \pm 32.51$ & $139.57 \pm 36.96$ & $\mathbf{0 . 6 5 3}$ & $148.18 \pm 31.39$ & $131.93 \pm 37.31$ \\
\hline $\begin{array}{l}\text { Serum LDL- } \\
\text { Cholesterol }\end{array}$ & $126.4 \pm 43.55$ & $49.9 \pm 15.31$ & $58.0 \pm 20.51$ & $\mathbf{0 . 1 2 8}$ & $136.47 \pm 43.81$ & $102.57 \pm 32.55$ \\
\hline $\begin{array}{l}\text { Serum HDL- } \\
\text { Cholesterol }\end{array}$ & $52.5 \pm 17.47$ & $137.5 \pm 41.40$ & $102.6 \pm 38.55$ & $\mathbf{0 . 2 3 3}$ & $51.13 \pm 17.92$ & $55.84 \pm 16.05$ \\
\hline
\end{tabular}

Table 2: Compare means of lab indicators among Ischemic \& Haemorrhagic Stroke groups and among Diabetic and non-diabetic stroke groups $(N=148)$

\section{Discussion}

The main findings of current study was reported that around two-third $(68.2 \%)$ of the study stroke patients had ischemic stroke and nearly onethird had haemorrhagic stroke (31.8\%). In other words Ischemic stroke was 2.1 times higher than haemorrhagic stroke. Similar findings were reported by a study conducted at a tertiary care hospital in Lahore and reported that $78 \%$ of study patients had ischemic stroke and $22 \%$ were haemorrhagic stroke ${ }^{17}$. Consistent finding were also reported by other hospital based studies that reported 22-31\% haemorrhagic stroke [18-20].

Prevalence of diabetes was found $70 \%$ in study stroke patients, mostly diagnosed during the routine investigation of stroke in hospital. Similar high prevalence was also reported by a study conducted at a tertiary care hospital in Lahore by Qureshi and revealed that the presence of diabetes in study stroke patients was $52.5 \%$ [17]. Diabetes was more prevail in ischemic stroke (78\%) 3.5 times higher as compare to haemorrhagic stroke $(22 \%)$. A Framingham heart study reported the similar finding as the incidence of ischemic stroke has been found to be from 2.5- to 3.5times higher among diabetic than among non-diabetic subjects [21]. Another study by Sarkar also reported that ischaemic stroke was higher in diabetic (69\%) than non-diabetic (45.8\%) [22]. This may be explained that diabetes mellitus is associated with accelerated atherogenesis [23], it is very likely that diabetes is a separate risk factor that plays an essential role in producing the vascular pathology underlying ischemic stroke.

Pattern of stroke in diabetic and non-diabetic stroke population was significantly different. Diabetes mellitus increases the risk of stroke 1.5 to 3 times higher as compare to non-diabetic population ${ }^{11}$. Diabetes may increase the risk of stroke in earlier age and also increase risk of stroke in women due to increase atherogenic risk within the extra and intra-cranial arteries and due to tendency of hyperglycaemia [11, 12]. Previous studies have provided the evidence that diabetic stroke patients were younger than non-diabetic stroke patients $[10,14,22,24]$. The current study reported the mean age of diabetic stroke patients was $50.67 \pm 8.74$ years and non-diabetic stroke patients was $51.88 \pm 11.78$. Diabetic stroke patients were 1.2 years younger than non-diabetic stroke patients, though difference was not statistically significant. A Copenhagen stroke study by Jorgensen [14] was reported the similar finding that the diabetic stroke patient was 3.2 years younger than the non-diabetic stroke patient $(\mathrm{P}<$ 0.001). Zafar et $\mathrm{al}^{10}$ also reported the mean age of diabetic stroke patients was $59.5 \pm 11.82$ and non-diabetic patients was $60.4 \pm 14.80$. Diabetic patient was 0.9 year younger than non-diabetic [10].
The current study reported high prevalence of hypertension (76\%), hyperlipidaemia (70\%), and smoking (46\%) among study stroke patients. These are established risk factors of stroke. When we compared these risk factors among diabetic and non-diabetic stroke patients, then only hyperlipidaemia was found statistically significant $(\mathrm{P}<0.05)$. On the other hand, when we compared these risk factors among ischemic and haemorrhagic stroke, the hypertension and hyperlipidaemia were statistically significant $(\mathrm{P}<0.05)$. High prevalence of hypertension $(66 \%)$ in stroke patients was also reported by Aga Khan University study ${ }^{18}$ and other studies such as OXVASC (55.9\%), OCSP $(65.5 \%)$ [23, 24].

Regarding prognosis of stroke, the current study reported $25 \%$ stroke related deaths in hospital. Previous studies have reported the stroke related mortality in the range of $11-30 \%[17,19,25,26]$. Deaths were more in haemorrhagic stroke (36\%) as compared to ischemic stroke (20\%) ( $\mathrm{P}<0.05)$. But no significant difference in deaths related to diabetes versus non-diabetes stroke patients were found.

Study Limitations: Current study was small sample size with convenient sampling due to time and financial constraint. Therefore, this study data was not extrapolated on general population. Strokes other uncommon risk factors like atrial fibrillation, carotid artery stenosis, peripheral vascular disease, use of oral contraceptive pills (OCP) by women study participant and obesity were not investigated due to low frequency of these findings among study patients were reported in previous study [27].

\section{Conclusion}

Ischemic stroke was more common than haemorrhagic stroke among study stroke patients. Diabetes was found in majority stroke patients particularly in ischemic stroke patients. Diabetes exacerbated the risk of stroke in younger people. Hypertension, hyperlipidemia and smoking were found as a major risk factors in the study stroke patients. Prognosis of stroke was bad particularly in haemorrhagic stroke patients.

\section{References}

1. Sander D, Sander K, Poppert H (2008) Stroke in type 2 diabetes. Br J Diabetes Vasc Dis; 8: 222-229.

2. World Health Organization. The Atlas of Heart Disease and Stroke (2013)

3. Das SK, Banerjee TK, Biswas A, Roy T, Raut DK, et al (2007) A prospective community-based study of stroke in Kolkata, India. Stroke; 38: 906-910. 
4. Liu M, Wu B, Wang WZ, Lee LM, Zhang SH (2007) Stroke in China: Epidemiology, prevention and management strategies. Lancet Neurol 6: 456-464.

5. Jafar TH (2006) Blood pressure, diabetes and increased dietary salt associated with stroke- results from a community-based study in Pakistan. J Hum Hypertens 20: 83-85.

6. Pakistan stroke society. Information about stroke [Online]. 2006.

7. Sims NR, Muyderman H (2009) Mitochondria, oxidative metabolism and cell death in stroke. Biochimica et Biophysica Acta 1802(1): 80-91.

8. Donnan GA, Fisher M, Macleod M, Davis SM (2008) Stroke. Lancet 371(9624): 1612-1623.

9. National Institute of Neurological Disorders and Stroke. Bethesda, US. Brain Basics: Preventing Stroke [Online]. 2013.

10. Zafar A, Shahid SK, Siddiqui M, Khan FS (2007) Pattern of stroke in type 2 Diabetic subjects versus non-diabetic. J Ayub Med Coll 19(4): 64-67.

11. Bejot Y, Giroud M (2010) Stroke in diabetic patients. Diabetes Metab 36 Suppl 3: S84-S87.

12. Kissela BM, Khoury J, Kleindorfer D. Epidemiology of ischemic stroke in patients with diabetes: the greater Cincinnati/Northern Kentucky Stroke Study. Diabetes Care 2005;28:355-359

13. Mankovsky BN, Metzger BE, Molitch ME, Biller J (1996) Cerebrovascular disorders in patients with diabetes mellitus. J Diabetes Complications 10: 228-242.

14. Jorgensen H, Nakayama H, Raaschou HO, Olsen TS (1994) Stroke in patients with diabetes. The Copenhagen Stroke Study. Stroke 25: 1977-1984.

15. World Health Organization: WHO Study Group on Diabetes Mellitus Geneva, Switzerland: World Health Organization; 1985:103-108. Technical Report Series no 722.

16. Scott M. G, Diane B, Luther C, Richard SC, Margo A, et al (2002) Evaluation, and treatment of high blood cholesterol in adults (adult treatment Panel III). The National Cholesterol Education Program Expert Panel on Detection

17. Qureshi MA, Jamshaid TD, Siddiqui AM (2003) Stroke-A study of clinical patterns and risk factors. Ann King Edward Med Coll Jun 9(2): 98-100.

18. Syed NA, Khealani BA, Ali S, Hasan A, Akhtar N, et al (2003) Ischemic stroke subtypes in Pakistan: the Aga Khan University Stroke Data Bank. J Pak Med Assoc. 53: 584-588.

19. Vohra EA, Ahmed WU, Ali M (2000) Aetiology and prognostic factors of patients admitted for stroke. J Pak Med Assoc. 50: 234236.

20. Khan SN, Vohra EA (2007) Risk factors of stroke: A hospital based study. Pak J Med Sci 23:17-22.

21. Kannel WB, McGee DL (1979) Diabetes and cardiovascular disease: The Framingham Study. JAMA. 241:2035-2038.

22. Sarkar RN, Banerjee S, Basu A (2004) Comparative evaluation of diabetic and non-diabetic stroke. Effect of glycaemia on outcome. J Indian Med Associ 102(10): 551-553.

23. Bell DSH (1994) Stroke in the diabetic patient. Diabetes Care 17: 213-219.

24. Megherbi SE, Milan C, Minier D. (2003) Association between diabetes and stroke subtype on survival and functional outcome 3 months after stroke: data from the European BIOMED Stroke Project. Stroke 34: 688-694.

25. Alam I, Haider I, Wahab F, Khan W, Taqweem MA, et al (2004) Risk factors stratification in 100 patients of acute Stroke. J Postgrad Med Inst; 18: 583-591.

26. Ahmed R, Shakir AH, Moizuddin SS, Haleem A, Ali S, et al (2001) Predictors of in hospital mortality for intracerebral hemorrhage: A hospital based study in Pakistani adults. J Stroke Cerebrovasc Dis. 10: 122-27.

27. Khan H, Afridi AK, Ashraf S (2006). A hospital based study on stratification of risk factors of stroke in Peshawar. Pak J Med Sci; 22: 304-307.

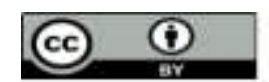

This work is licensed under Creative Commons Attribution 4.0 License
Ready to submit your research? Choose Auctores and benefit from:

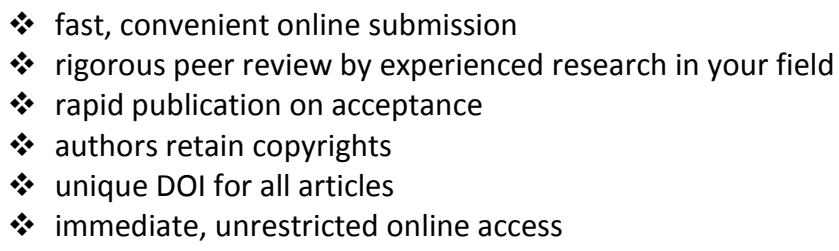

At Auctores, research is always in progress.

Learn more https://auctoresonline.org/journals/journal-of-clinical-casereports-and-studies 